\title{
Experimental Determination and Correlation of Liquid-Liquid Equilibria for Methyl Isopropyl Ketone + Phenol + Water Mixtures at 298.15, 313.15 and 323.15 $\mathrm{K}$
}

Ran Lv, Libo Li, Huimin Wang, and Yun Chen*

Key Laboratory of Heat Transfer Enhancement and Energy Conservation of Ministry of Education, School of Chemistry and Chemical Engineering, South China University of

Technology, Guangzhou, 510640, P.R.China

Supporting Information

(a)

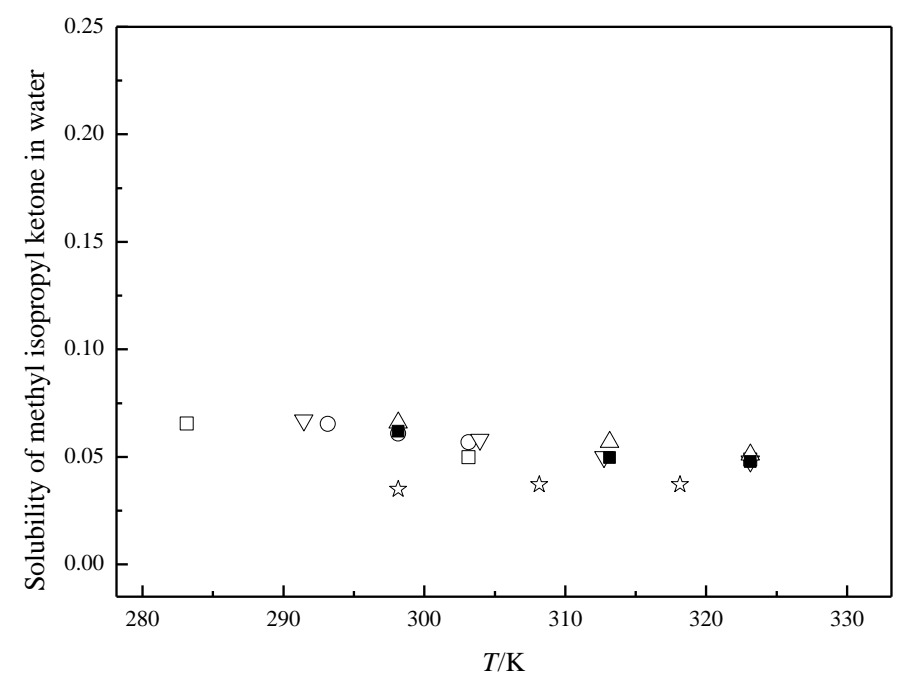




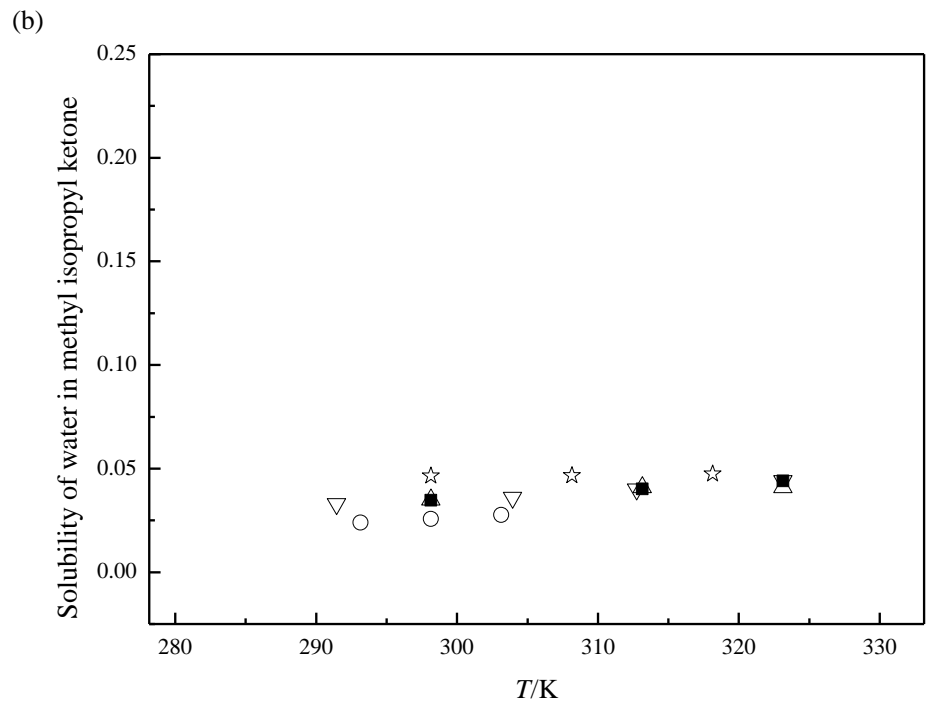

Figure S1. Comparisons of experimental solubility of methyl isopropyl ketone in water (a) and experimental solubility of water in methyl isopropyl ketone (b) with that reported in literature: $\mathbf{m}$, experimental data; $\square$, literature data from Gross et al. ${ }^{28} \circ$, literature data from Ginnings et al. ${ }^{29} \Delta$, literature data from Bozdag and Lamb; ${ }^{30} \nabla$, literature data from Stephenson $;^{31} \mathcal{i}$, literature data from Taghikhani et al.. ${ }^{32}$

\section{References}

(28) Gross, P. M.; Rintelen, J. C.; Saylor, J. H. Energy and Volumn Relations in the Solubilities of Some Ketones in Water. J. Phys. Chem. 1939, 43, 197-205.

(29) Ginnings, P. M.; Plonk, D.; Cater, E. Aqueous Solubilities of Some Aliphatic Ketones. J. Am. Chem. Soc. 1940, 62, 1923-1924.

(30) Bozdag, O.; Lamb, J. A. Liquid-Liquid Phase Equilibria in the 3-Methyl-2-Butanone + Water System at High Pressure. Fluid Phase Equilib. 1981, 6, 191-201.

(31) Stephenson, R. M. Mutual Solubilities: Water-Ketones, Water-Ethers, and WaterGasolione-Alcohols. J. Chem. Eng. Data 1992, 37, 80-95.

(32) Taghikhani, V.; Vakili-Nezhaad, G. R.; Khoshkbarchi, M. K.; Shariaty-Niassar, M. Liquid-Liquid Equilibria of Water + Propionic Acid + Methyl Butyl Ketone and of Water + Propionic Acid + Methyl Isopropyl Ketone. J. Chem. Eng. Data 2001, 46, 1107-1109. 